\title{
Episodic simple shear tests to measure strength changes for whole-life geotechnical design
}

\author{
N.I. LAHAM*, K.A. KWA*, D.J. WHITE* and S.M. GOURVENEC*
}

\begin{abstract}
This technical note describes a set of direct simple shear (DSS) tests that characterise the evolving geotechnical properties of a soft soil, through a loading history that represents episodic loading and consolidation periods as encountered by some offshore infrastructure. The interpretation uses a critical state soil mechanics (CSSM) framework. CSSM provides the necessary building blocks to quantify the balance between undrained cyclic loading and the associated increases in pore pressure, and drainage and consolidation, leading to strength regain. The results show how DSS tests can characterise the through-life response of soft clays. The measured responses showed the changing strength of the clay due to consolidation effects following loading, and match predictions from simple models. The results show how DSS tests can characterise the types of behaviour also seen in centrifuge models and field penetrometer tests related to the long-term response of soft clays under offshore infrastructure.
\end{abstract}

KEYWORDS: clays; footings/foundations; offshore engineering

Published with permission by the ICE under the CC-BY 4.0 license. (http://creativecommons.org/licenses/by/4.0/)

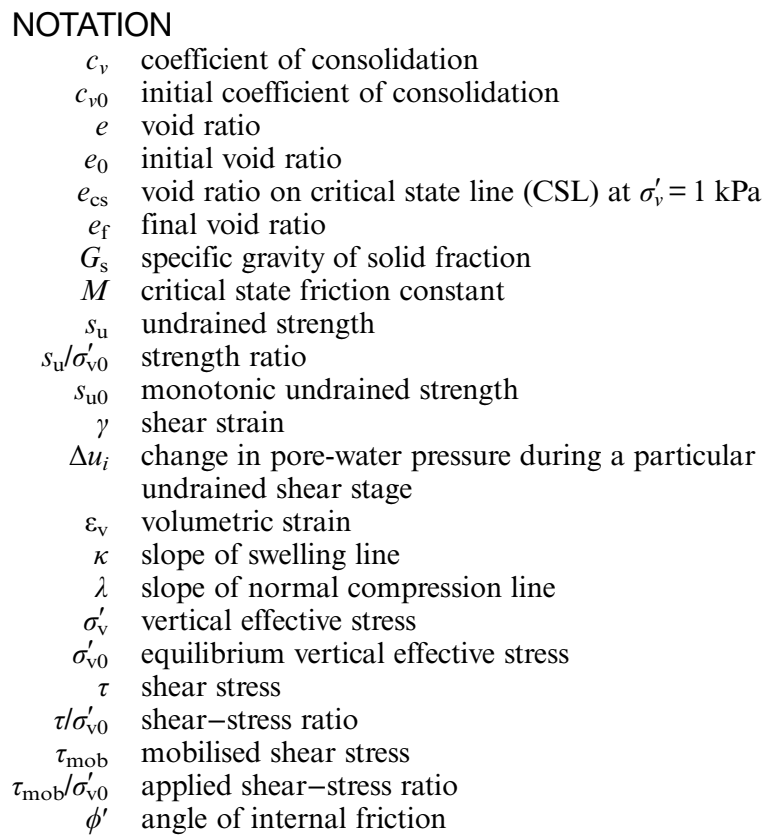

\section{INTRODUCTION}

Offshore infrastructure for renewable energy and oil and gas production is subjected to a range of actions from metocean and operational conditions. These actions are transmitted by way of structures, mooring lines or pipelines to foundation or anchoring systems. These loads can affect the geotechnical properties of the seabed and in turn affect the capacity and response of the infrastructure over its lifetime (Gourvenec, 2020). Whole-life geotechnical design couples the life cycle

Manuscript received 9 September 2020; first decision 30 November 2020; accepted 1 December 2020.

Published online at www.geotechniqueletters.com on 8 December 2020.

*University of Southampton, Southampton, UK. of imposed actions with the evolving geotechnical resistance, to forecast the soil-structure response across the design life of the infrastructure. It is essential to reliably estimate the changing available seabed resistance and stiffness throughout the whole life of the structure to predict its response and optimally design and manage the asset. Transient, sustained, cyclic or episodic actions can affect the strength, stiffness and consolidation parameters of the seabed leading to variations in 'current' seabed resistance and the system reliability over the whole life of the structure. Allowing for these changes can have a beneficial design outcome, offering opportunities for more efficient systems including reductions in foundation or anchoring size, reduced risk of fatigue, greater insight for late life management and informed decommissioning processes for offshore infrastructure (Gourvenec, 2020).

It is well recognised that sustained monotonic compressive loading can improve geotechnical resistance through consolidation while undrained cyclic loading may reduce resistance through cyclic softening. Models for both cases are well established in engineering practice (e.g. Schofield \& Wroth, 1968; Andersen, 2015). The strength and stiffness of soft soils is also affected by consolidation during continuous cyclic loading of sufficiently long duration, and by episodic loading that involves cyclic loads with intervening consolidation. Such loading could be caused by intervals of bad weather or by operating cycles such as heating and cooling of pipelines. In soft clay, these processes generally increase the subsequent undrained strength and stiffness. Whole-life effects of changing soil properties have been observed during flow round penetrometer tests (Hodder et al., 2013; Cocjin et al., 2014; O'Loughlin et al., 2017), interface shear tests (Boukpeti \& White, 2017) and large-scale laboratory tank tests and geotechnical centrifuge tests of pipelines, sliding foundations (Cocjin et al., 2014, 2017; Smith \& White, 2014; Han et al., 2016; Zhou et al., 2019; Lai et al., 2020) and pile foundations (Bayton et al., 2018; Richards et al., 2018, 2019; Abadie et al., 2019; Truong et al., 2019). Applications and impact of whole-life geotechnical design are summarised in Gourvenec $(2018,2020)$. 
For wider application of whole-life geotechnical design to offshore geotechnical infrastructure, a more accessible, cost-effective and established method of characterising whole-life geotechnical responses is necessary, beyond the model testing example above. This technical note explores the potential for characterising evolving geotechnical properties - strength, stiffness and consolidation parameters through extended direct simple shear (DSS) tests. The DSS test is commonly used in offshore geotechnical site investigation due to smaller required sample size compared to triaxial testing, and because it produces an intermediate soil strength between triaxial compression and extension, which is appropriate if a single measured value is to be used for foundation capacity assessment (Kinner \& Ladd 1973; Mayne, 1985; Randolph, 2000).

\section{EXPERIMENTAL DETAILS}

\section{DSS apparatus}

A suite of DSS tests was performed at the University of Southampton using a Global Digital Systems (GDS)

Table 1. Characteristics of kaolin clay

\begin{tabular}{l|c}
\hline Property & Value \\
\hline Liquid limit (LL): \% & 61 \\
Plastic limit (PL): \% & 27 \\
Specific gravity $G_{\mathrm{s}}$ & $2 \cdot 7$ \\
Void ratio at $\sigma_{\mathrm{v}}^{\prime}=1 \mathrm{kPa}$ on CSL $e_{\mathrm{cs}}$ & 2 \\
Slope of normal consolidation line $\lambda$ & $0 \cdot 15$ \\
Slope of swelling line $\kappa$ & $0 \cdot 05$ \\
Angle of internal friction $\phi^{\prime:}$ & 24 \\
\hline
\end{tabular}

Instruments $10 \mathrm{kN}$ electromechanical dynamic cyclic simple shear (EMDCSS) apparatus. This DSS apparatus has two linear actuators controlling vertical movement of the loading ram, and horizontal movement at the base of the sample. These linear actuators are connected to displacement transducers and load cells by way of a feedback loop, enabling displacement- and load-controlled testing. Teflon-coated, stainless-steel stacked rings surround the specimen to impose a zero lateral strain boundary condition.

The apparatus deformation and lateral confinement system were calibrated immediately prior to the test programme and all vertical displacements and shear stresses have been corrected based on these calibrations in agreement with ASTM D 6528-07 (ASTM, 2007). A GDS pressure controller was used to measure pore-water pressures in the sample, connected by way of drainage holes in the top and bottom platens. The pressure controller and lines were flushed and refilled with de-aired water before each test to ensure minimal air was present in the system.

\section{Specimen preparation and assembly}

Reconstituted kaolin, with properties listed in Table 1, was prepared as a slurry at a water content twice the liquid limit and mixed under a vacuum for $24 \mathrm{~h}$ before being transferred to a $105 \mathrm{~mm}$ diameter tube and consolidated in increments to a maximum vertical stress of $60 \mathrm{kPa}$. This stress level was chosen to target the minimum strength that is practical for sample preparation and to give soil strengths representative for shallow soft clay.

The stress increments were applied for $12 \mathrm{~h}$ and the final increment was applied for at least $24 \mathrm{~h}$. Individual specimens were extruded from the tubes of consolidated kaolin and

Table 2. Summary of DSS tests

\begin{tabular}{|c|c|c|c|c|c|c|c|}
\hline $\begin{array}{l}\text { Test } \\
\text { name }\end{array}$ & $\begin{array}{c}\text { Initial } \\
\text { void ratio } \\
e_{0} \\
\end{array}$ & $\begin{array}{l}\text { Final } \\
\text { void } \\
\text { ratio, } e_{f}\end{array}$ & $\begin{array}{c}\text { Applied vertical } \\
\text { consolidation stress, } \\
\sigma_{\mathrm{v} 0}^{\prime}: \mathrm{kPa} \\
\end{array}$ & $\begin{array}{c}\text { Applied cyclic } \\
\text { stress ratio } \\
\tau_{\mathrm{mob}} / \sigma_{\mathrm{v} 0}^{\prime} \\
\end{array}$ & $\begin{array}{c}\text { Final } \\
\text { strength } \\
\text { ratio } s_{\mathrm{u}} / \sigma_{\mathrm{v} 0}^{\prime} \\
\end{array}$ & $\begin{array}{l}\text { Vertical } \\
\text { effective stress } \\
\text { at failure: } \mathrm{kPa} \\
\end{array}$ & $\begin{array}{l}\text { Final undrained } \\
\text { strength, } s_{\mathrm{u}}: \mathrm{kPa}\end{array}$ \\
\hline M62 & $1 \cdot 38$ & $1 \cdot 29$ & 62 & —* & $0 \cdot 24$ & $32 \cdot 6$ & $14 \cdot 9$ \\
\hline M90 & $1 \cdot 35$ & $1 \cdot 24$ & 90 & —* & $0 \cdot 27$ & $56 \cdot 6$ & $24 \cdot 2$ \\
\hline E63-0.67 & $1 \cdot 36$ & $1 \cdot 20$ & 63 & $0 \cdot 17$ & $0 \cdot 35$ & $50 \cdot 2$ & $21 \cdot 8$ \\
\hline E72-0.70 & $1 \cdot 37$ & $1 \cdot 18$ & 72 & $0 \cdot 18$ & $0 \cdot 36$ & $58 \cdot 2$ & $25 \cdot 7$ \\
\hline E75-0.48 & $1 \cdot 36$ & $1 \cdot 17$ & 75 & $0 \cdot 12$ & $0 \cdot 40$ & $70 \cdot 8$ & $30 \cdot 3$ \\
\hline
\end{tabular}

*Monotonic tests.

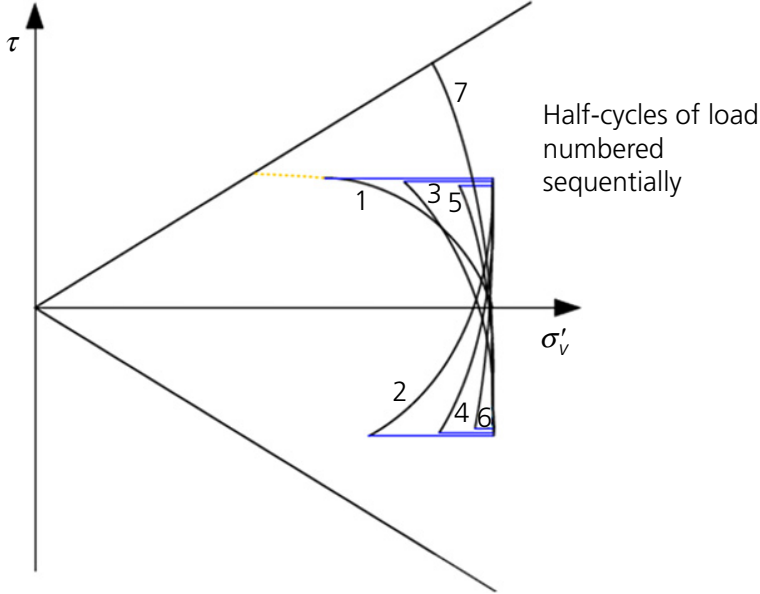

(a)

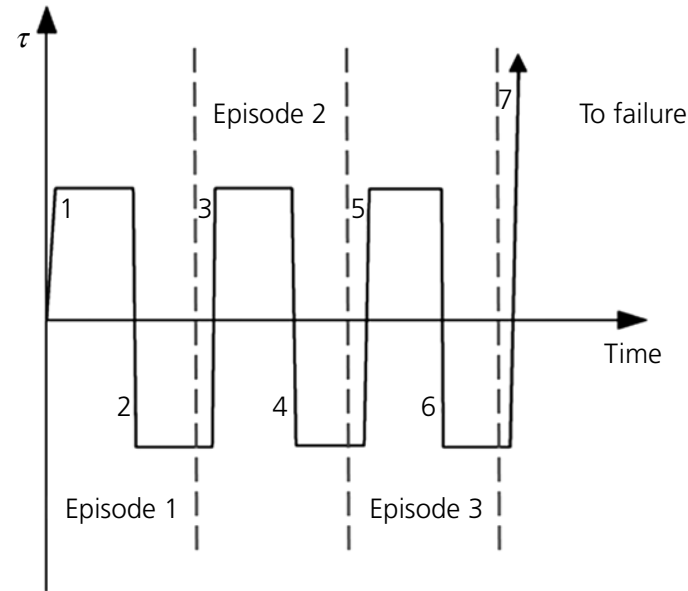

(b)

Fig. 1. Schematic of the (a) stress path in $\tau$ against $\sigma_{\vee}^{\prime}$ space and (b) shear stress loading pattern with time for episodic tests 
trimmed to size using a round, $100 \mathrm{~mm}$ diameter and $27 \mathrm{~mm}$ tall cutter. The specimens were pressed out of the sample cutter into the removable base of the DSS, where the metal stacked rings and rubber membrane had already been assembled. The base was gently placed and secured in the bottom of the DSS apparatus. The top of the DSS was

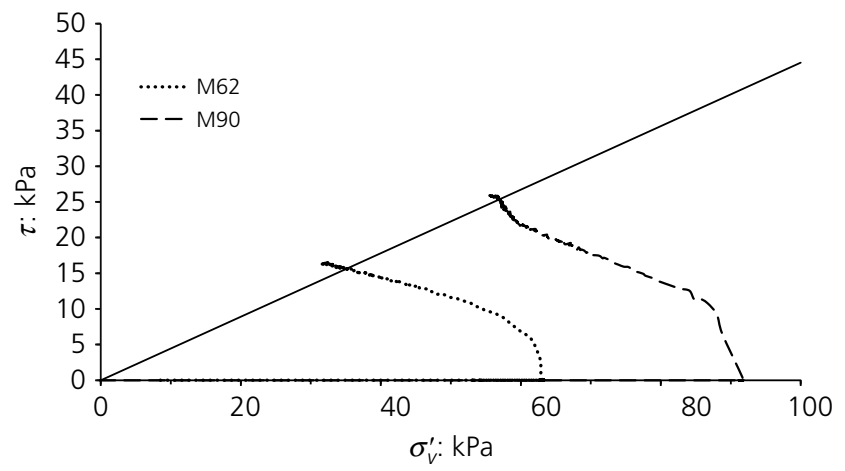

(a)

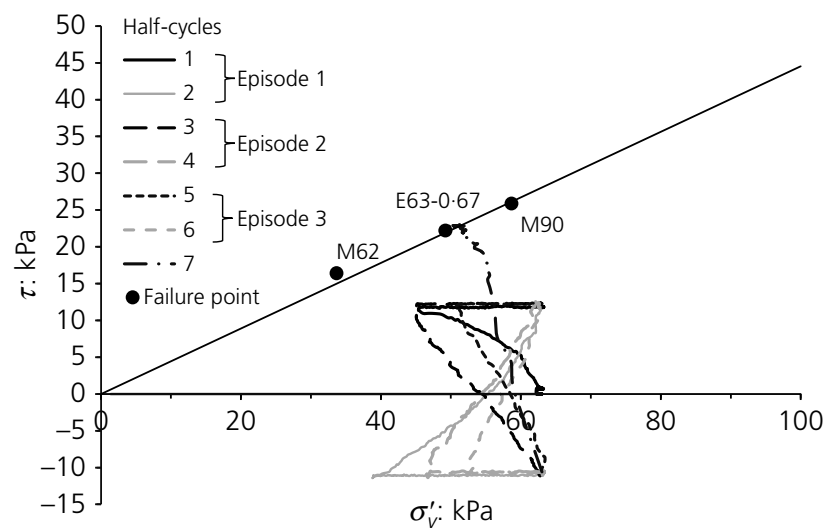

(b)

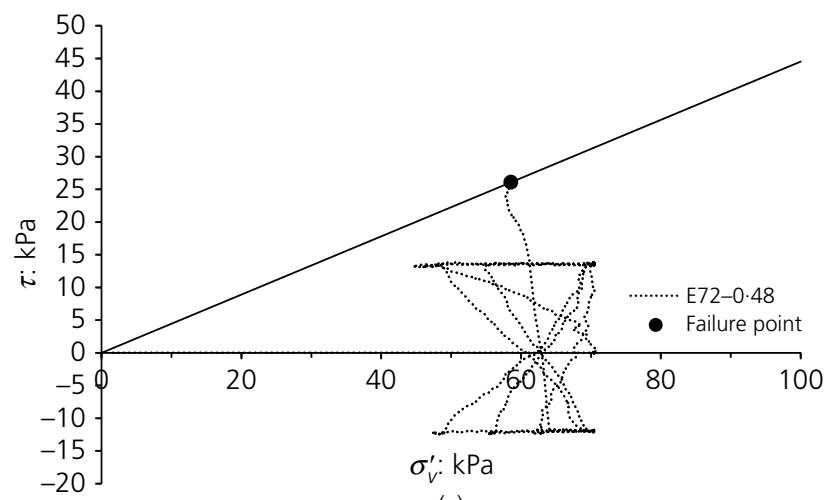

(c)

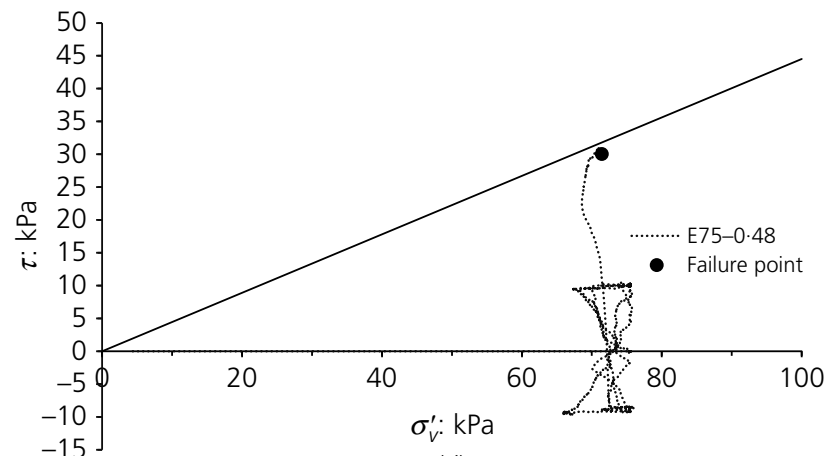

(d)

Fig. 2. Effective stress paths for (a) monotonic tests and (b), (c), (d) episodic tests lowered until the top platen was just touching the top of the sample. A small vertical stress $(<1 \mathrm{kPa})$ was applied as seating pressure and the settlements were monitored overnight to ensure the sample was no longer settling before the consolidation stage commenced. This displacement was included in the calculation of the final specimen height. Finally, the rubber membrane was pulled up and sealed with O-rings around the top and bottom platens.

\section{Testing programme and procedure}

Table 2 summarises the tests performed. The test labels indicate whether they were monotonically $(\mathrm{M})$ or episodically (E) sheared, and include the consolidated vertical effective stress and for the episodic tests, the applied shear-stress ratio, relative to the average strength ratio measured from the two monotonic tests $\left(s_{\mathrm{u}} / \sigma_{\mathrm{v} 0}^{\prime}=0 \cdot 255\right)$. The specimens were reconsolidated in the DSS apparatus following the procedure set out in ASTM D 6528-07 (ASTM, 2007). Consolidation was performed at $0 \cdot 1 \mathrm{kPa} / \mathrm{min}$, which ensured minimal pore-pressure build-up within the sample.

The monotonic tests were performed under displacement control at a rate of $0.1 \mathrm{~mm} / \mathrm{min}$ to assess the monotonic DSS strength in normally consolidated conditions. The applied stress path and cyclic shear loading procedure adopted in the episodic cyclic tests are illustrated in Fig. 1 and consisted of six episodes of undrained half-cycles with intervening consolidation stages, followed by a final monotonic, undrained shear stage (half-cycle 7) to failure.

The episodic tests were performed under stress control, at a rate of $0 \cdot 1 \mathrm{kPa} / \mathrm{min}$. The target shear stresses spanned a range of fractions of the monotonic strength, representative of soil elements close to an episodically loaded structure. Constant height conditions were applied during the shearing stages in both monotonic and episodic tests to ensure constant sample volume, according to the method outlined in Dyvik et al. (1987).

During the episodic consolidation stages, the vertical stress was returned to the original consolidation stress, drainage was then allowed and the volume of water that flowed out of the sample was measured by way of the pressure controller. Sample settlement was monitored and was typically complete within an hour. Finally, the undrained shear stage to failure was controlled at a displacement rate of $0 \cdot 1 \mathrm{~mm} / \mathrm{min}$.

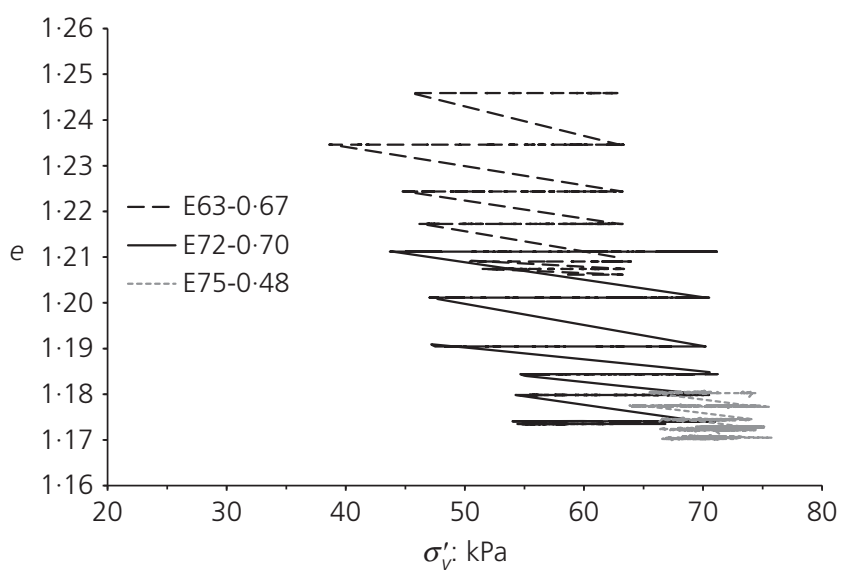

Fig. 3. Change in volume due to shear and consolidation for varying initial states and applied shear stresses 


\section{RESULTS}

\section{Shearing response}

The effective stress paths during monotonic tests M62 and M90 in Fig. 2(a) show a rise in pore-water pressure as the effective stress falls, and the state moves to the critical state line (CSL). Similar stress paths were followed in the first half-cycle of the episodic tests (Figs 2(b)-2(d)). With further episodes of consolidation and shearing, the build-up in pore-water pressure decreased, similar to the idealised effective stress path shown in Fig. 1.

The episodic test E63-0.67 shown in Fig. 2(b), failed at a higher shear stress, and denser state than the monotonic test M62 with the same initial conditions, demonstrating the gain in strength with episodes of undrained shear and consolidation. The final undrained strengths achieved in E72-0.70 and E75-0.48 were greater than M90, with the

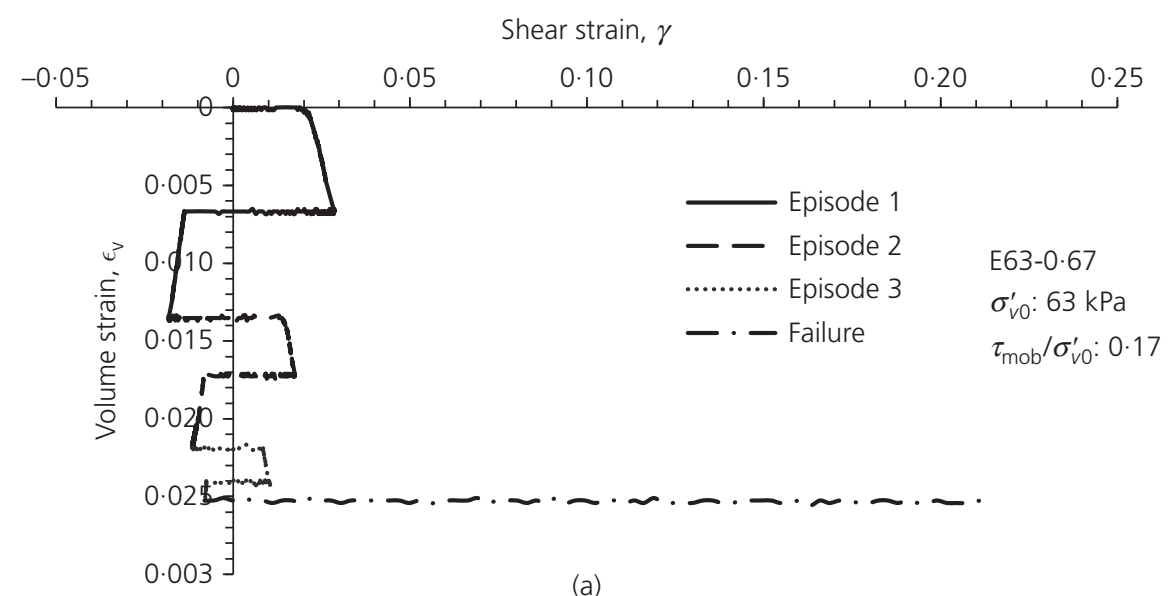

(a)

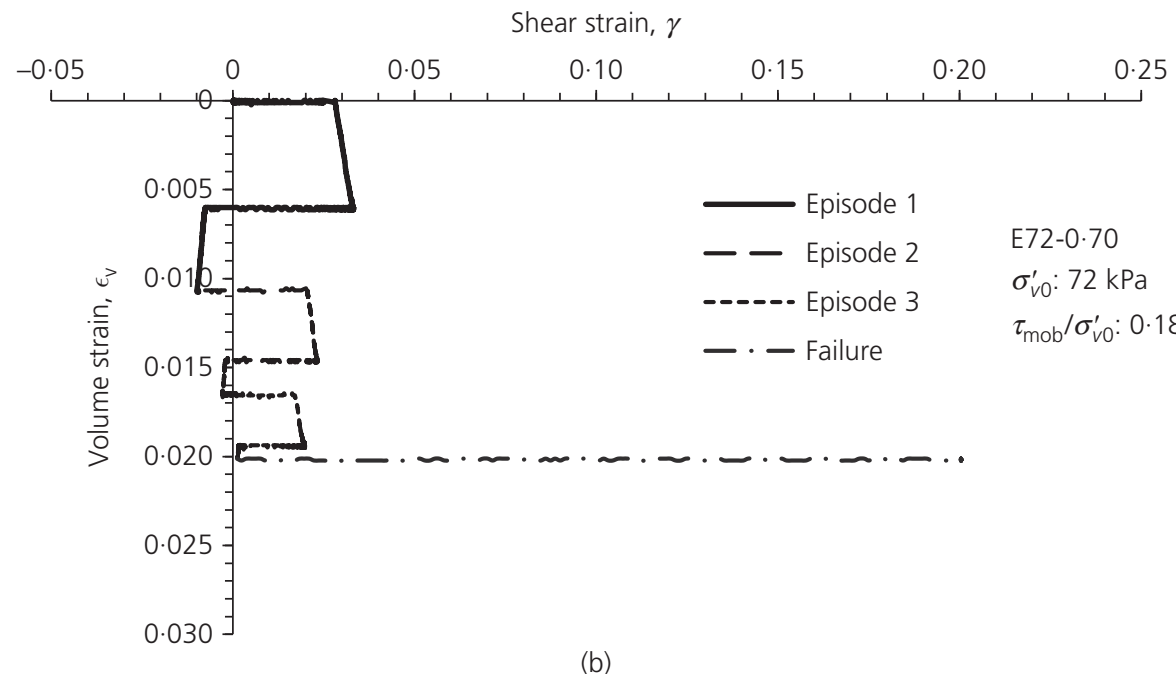

Shear strain, $\gamma$

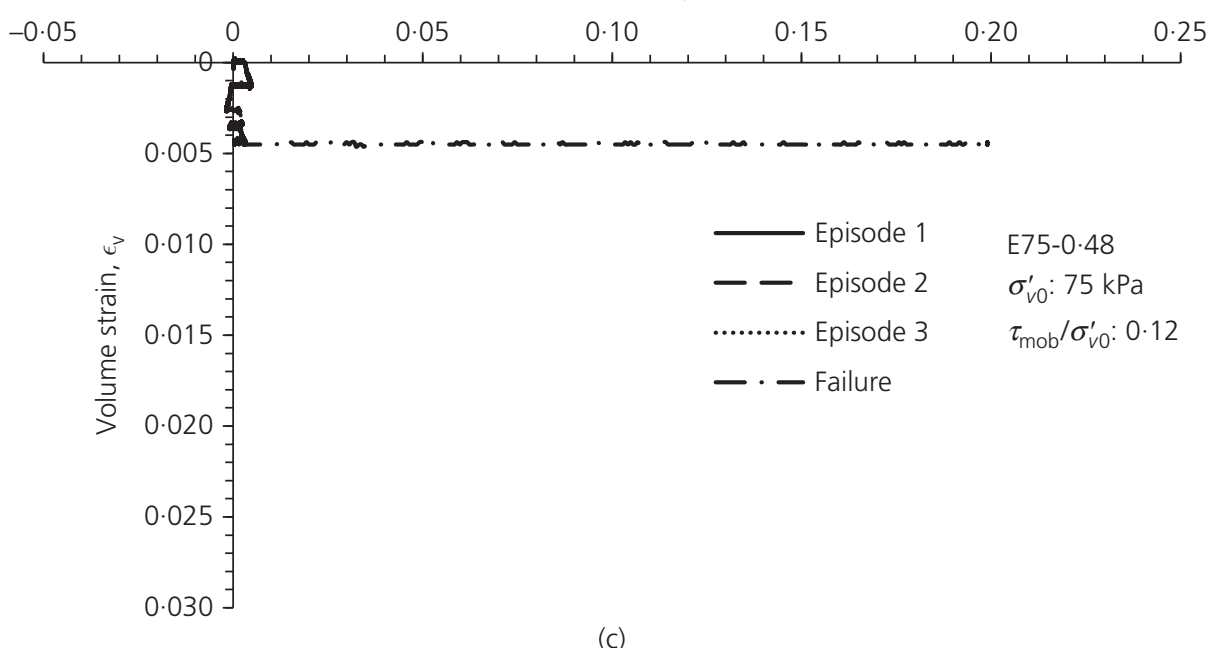

(c)

Fig. 4. Evolution of compressibility and stiffness for episodically sheared samples: (a) E63-0.67; (b) E72-0.70 and (c) E75-0.48 
intervening consolidation stage in these cyclic tests eclipsing the higher consolidation stress in M90.

\section{Volumetric response}

The changes in effective vertical stress during shear and the changes in void ratio during consolidation both decreased with each subsequent episode of undrained shear and consolidation (Fig. 3). This reflects the sample becoming denser, stiffer and experiencing smaller increases in pore pressure, due to a reducing tendency to contract.

Stiffening from each cycle of shear and consolidation was also observed in the volumetric and shear strains, which decreased with each episode, as shown in Figs 4 and 5.

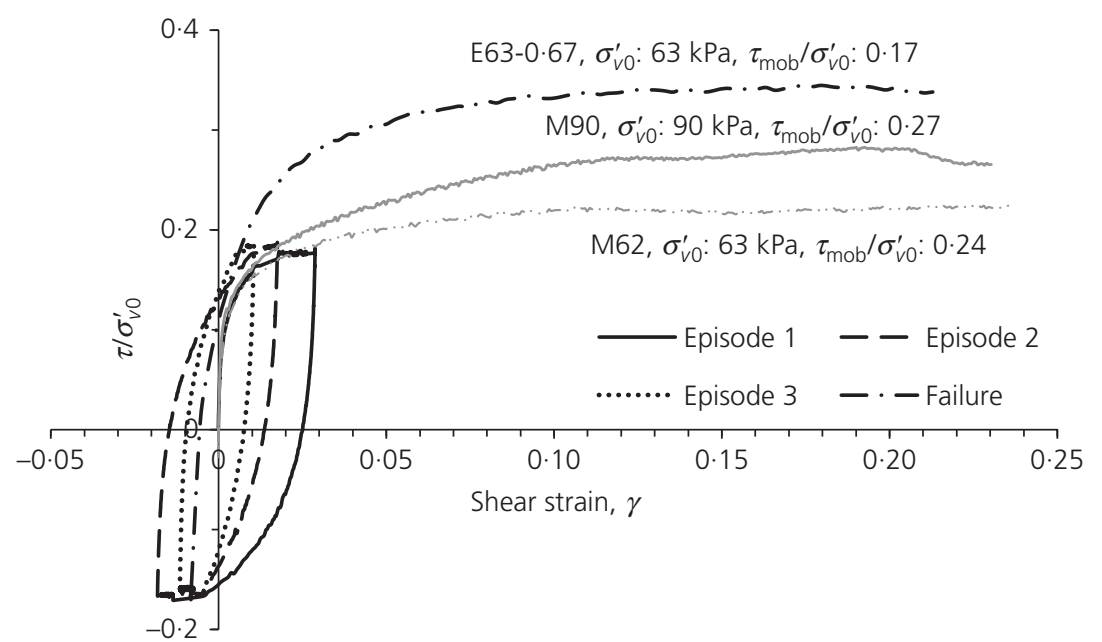

(a)

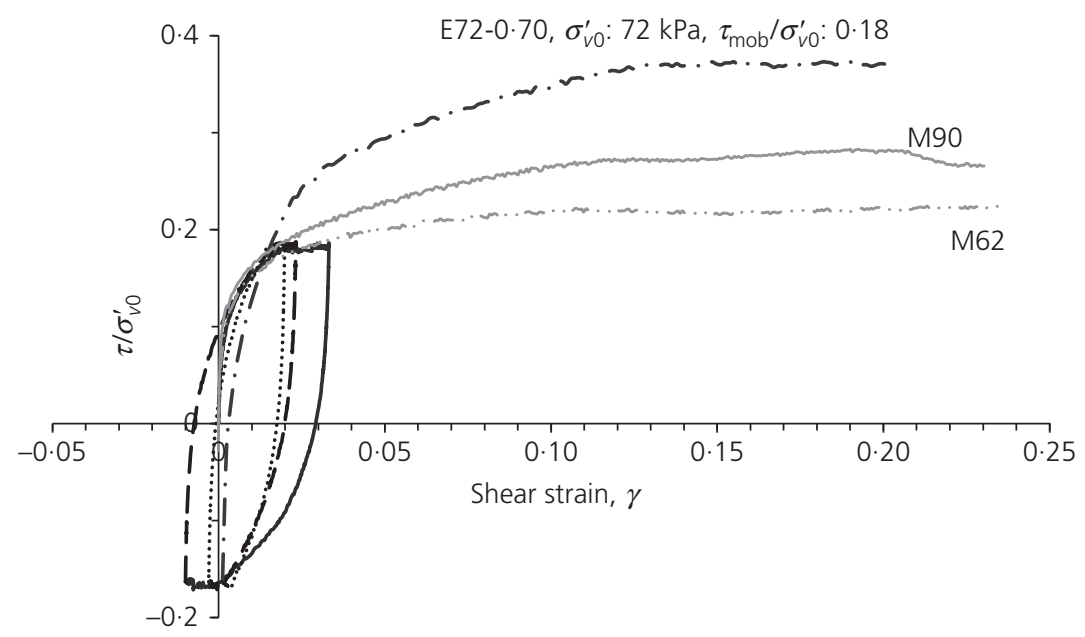

(b)

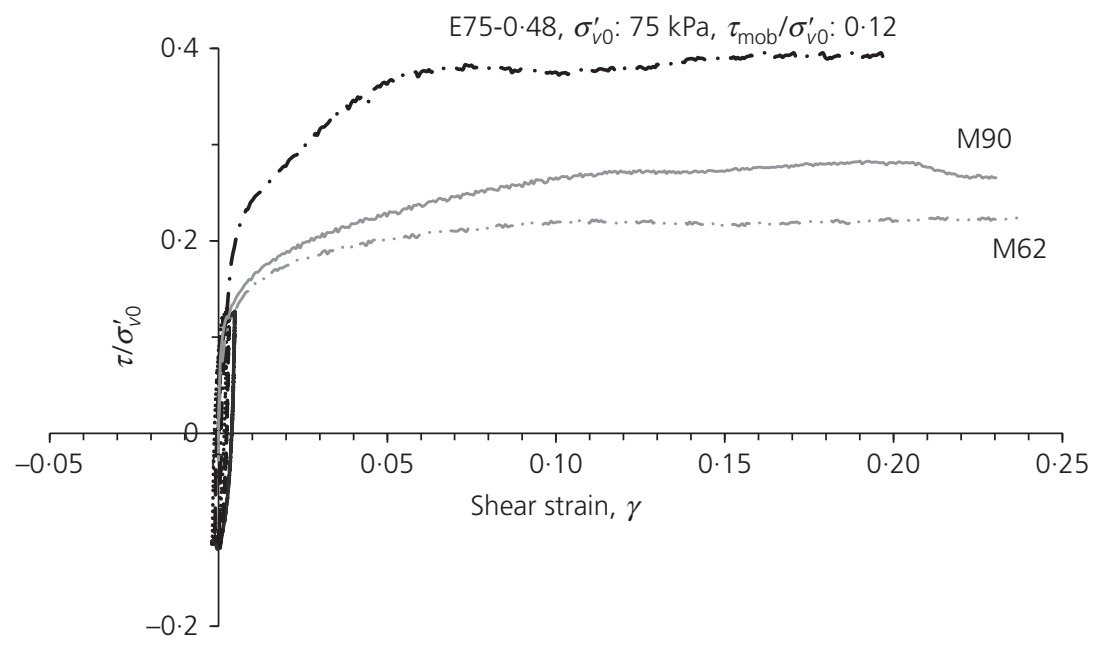

(c)

Fig. 5. Comparison of stress-strain behaviour between monotonically and episodically sheared samples: (a) E63-0.67; (b) E72-0.70 and (c) E75-0.48 


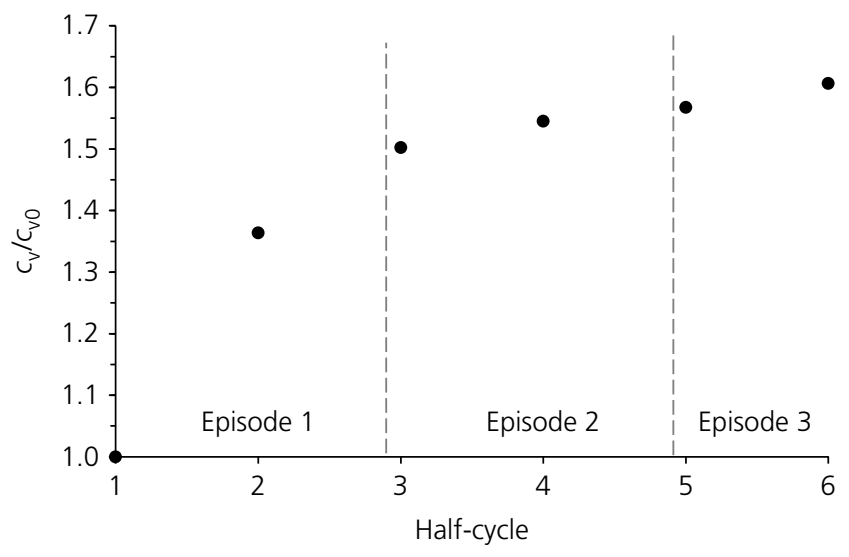

Fig. 6. Normalised evolution of consolidation coefficient $\left(c_{\mathrm{v}}\right)$ (test E72-0.48)

As samples compressed and stiffened, updated values of the coefficient of consolidation, $c_{v}$, were quantified for each intervening stage of consolidation, as shown per half-cycle in Fig. 6, normalised using $c_{v} / c_{v 0}$ where $c_{v 0}$ was obtained after the first half-cycle of loading. These values of $c_{v}$ are calculated using the Taylor root time method from the settlement response during each reconsolidation stage (Taylor, 1948). The largest increase in $c_{v}$ occurred from episode 1 to episode 2, when the samples experienced the largest volume strains and increase in stiffness. An implication of this trend is that changes in strength due to this type of episodic loading will happen at an increasing rate, due to the faster consolidation rate following each cycle of shear and consolidation. A rate of consolidation estimated using the initial value, $c_{v 0}$, would underestimate the effect.

\section{Calculated change in undrained strength}

Three methods for predicting the ratio between the undrained strength before $\left(s_{\mathrm{u}, i}\right)$ and after $\left(s_{\mathrm{u}, i+1}\right)$ an episode of shearing and consolidation have been compared with the test results.

Method 1 uses the measured changes in void ratio according to equation (1) (Schofield \& Wroth, 1968):

$$
\frac{s_{\mathrm{u}, i+1}}{s_{\mathrm{u}, i}}=\exp \left(\frac{e_{i}-e_{i+1}}{\lambda}\right)
$$

Method 2 uses the measured pore pressures and a construction in $e$ against $\sigma_{v}^{\prime}$ space (Fig. 7) from Yasuhara \& Andersen (1991):

$$
\begin{aligned}
\frac{s_{\mathrm{u}, i+1}}{s_{\mathrm{u}, i}} & =\frac{\sigma_{v, \mathrm{fi}+1}^{\prime}}{\sigma_{v, \mathrm{fi}}^{\prime}}=\left(\frac{\sigma_{v, i+1}^{\prime}}{\sigma_{v, i}^{\prime}}\right)^{\kappa / \lambda}=\left(\frac{\sigma_{v 0}^{\prime}}{\sigma_{v 0}^{\prime}-\Delta u_{i}}\right)^{\kappa / \lambda} \\
& =\left(\frac{1}{1-\left(\Delta u_{i} / \sigma_{v 0}^{\prime}\right)}\right)^{\kappa / \lambda}
\end{aligned}
$$

A limitation of methods 1 and 2 is that the DSS test results are inputs. Method 3 avoids this limitation by applying equation (2) with an assumed effective stress path that varies with OCR: see Appendix for derivation (Yasuhara, 1994). This prediction method can therefore be validated or calibrated from test results, then applied to more general input loading conditions, including successive cycles of varying amplitude.

The predicted increases in undrained strength with each half-cycle from methods 1,2 and 3 were similar and the predicted undrained strength of the sample were close to the actual undrained strength achieved during half-cycle 7 (Fig. 8), for example using method 3 the predicted gain in

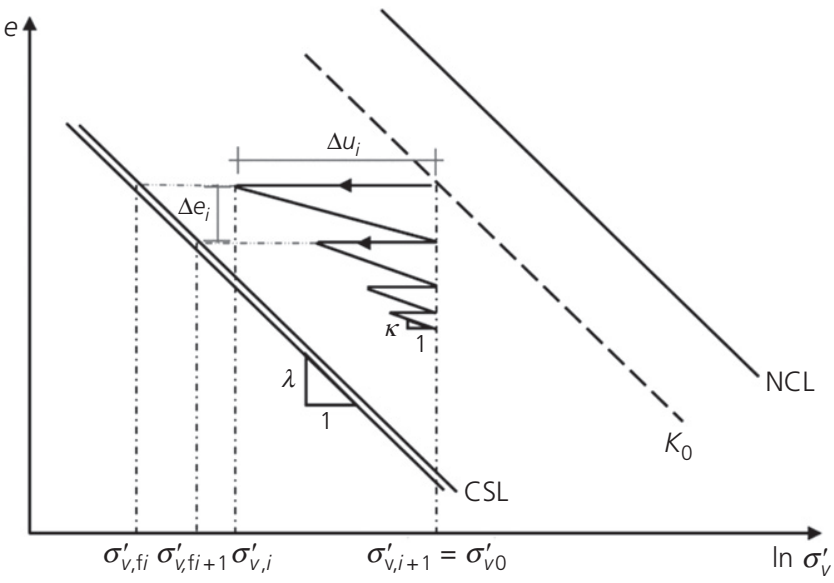

Fig. 7. Idealised effective stress path during undrained shear and intervening full consolidation

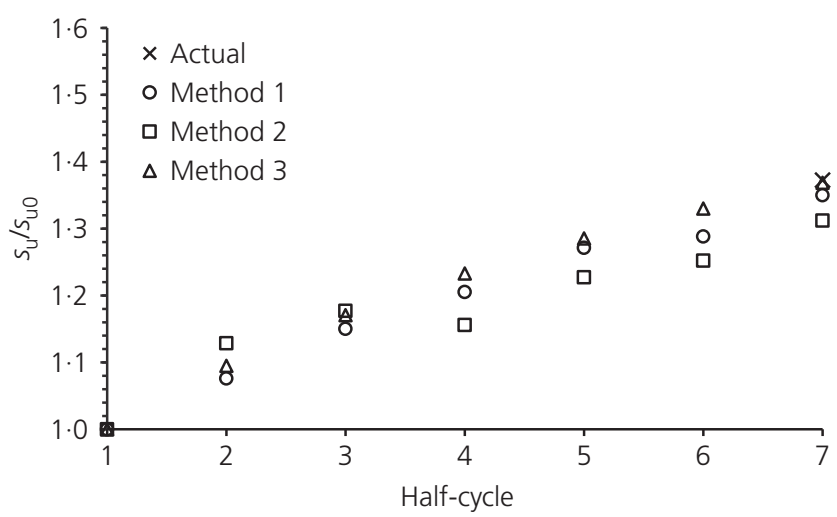

(a)

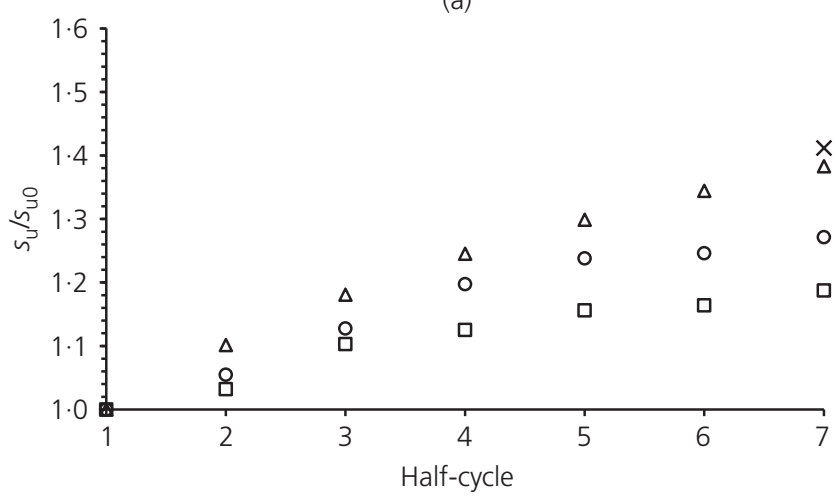

(b)

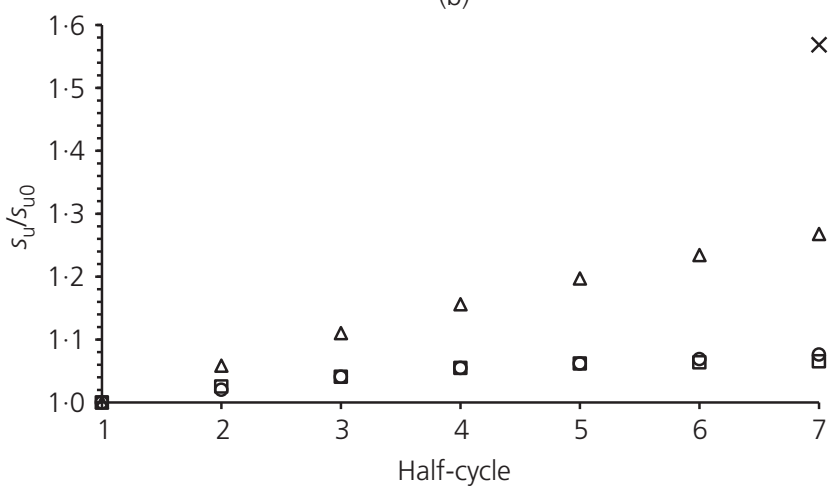

(c)

Fig. 8. Predicted and measured gains in undrained strength: (a) E63-0.67; (b) E72-0.70 and (c) E75-0.48 
$s_{\mathrm{u}} / s_{\mathrm{u} 0}$ is within $2 \%$ in tests E63-0.67 and E72-0.70. The variations between the predicted and actual strengths may be a result of the natural variability in the material properties, or due to inhomogeneities developing at the sample boundaries at large strains (>20\%) (Airey et al., 1985; Airey \& Wood, 1987), which were particularly noticeable in tests E72-0.70 and E75-0.48 and in the slight variation in stress paths between tests M62 and M90.

The results show consistent patterns of increasing undrained strengths during episodic loading as a result of the intervening consolidation stages, where drainage is permitted and samples become denser and stiffer. This behaviour is consistent with a simple CSSM-type predictive model, as well as the existing literature on the evolving properties of soft soils when subjected to loading conditions relevant to the whole-life response of offshore foundations (Gourvenec, 2018, 2020). Therefore, this DSS testing procedure is capable of characterising the evolving geotechnical properties and strengthening of soft soils.

\section{CONCLUSIONS}

This technical note presents the results from episodic DSS tests on reconsolidated soft clay, where each cycle consists of an undrained shear stage and a consolidation stage. These loading conditions are relevant to in-service conditions for a variety of offshore infrastructures, including shallow foundations, monopiles and plate anchors, and for a range of design approaches, including traditional factor of safety (FoS), tolerable mobility or performance-based design. The results showed that the strength, stiffness and consolidation coefficient of the clay increased due to consolidation effects that followed shear stages. These trends are consistent with observations from centrifuge models and field penetrometer tests representing the whole-life response of geotechnical offshore infrastructure. The DSS testing procedure, with benefits including small sample sizes, shorter consolidation times, and the ability to apply complex stress histories, can capture the evolving geotechnical properties in these conditions, and a simple predictive model can capture the observed changes in strength.

\section{ACKNOWLEDGEMENTS}

This study was supported through the Royal Academy of Engineering chair in Emerging Technologies in Intelligent \& Resilient Ocean Engineering, the EPSRC Supergen Offshore Renewable Energy Hub (EP/S000747/1) and the Erasmus Mundus Scholarship Programme. The authors are also grateful to Mr Harvey Skinner, Geomechanics Laboratory manager at the National Infrastructure Laboratory, University of Southampton, and Dr Fernando Alvarez Borges, for their technical assistance during the laboratory testing.

\section{APPENDIX}

Figures 9 and 10 show the parameters used.

Calculation of strength and definitions of OCR:

Initially, the sample is $K_{0}$ normally consolidated such that

$$
\sigma_{v c}^{\prime}=\sigma_{v 0}^{\prime}=\sigma_{v e}^{\prime}
$$

More generally, these values differ when the over consolidation ratio $(\mathrm{OCR}) \neq 1$. The undrained strength is then given by

$$
s_{\mathrm{u}}=R \sigma_{v e}^{\prime}
$$

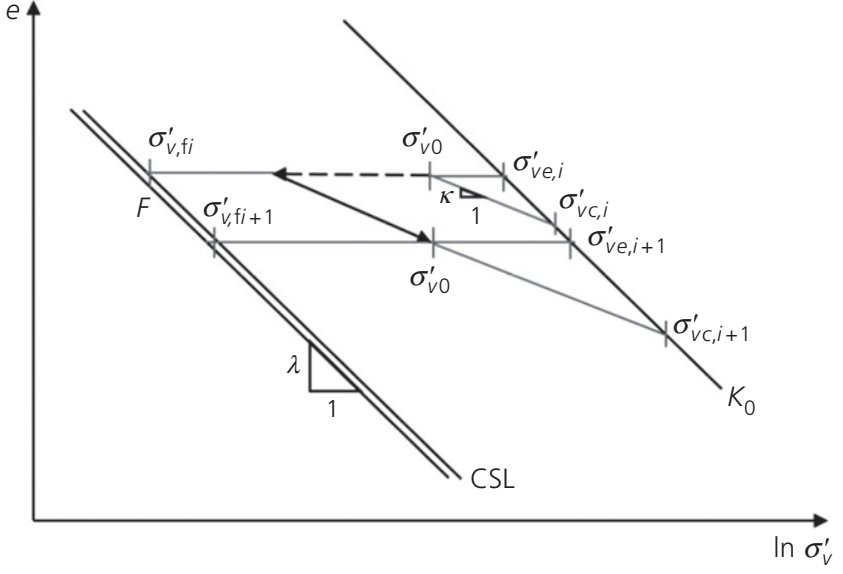

Fig. 9. Stress-voids ratio paths and notation in method 3 to predict changes in undrained strength

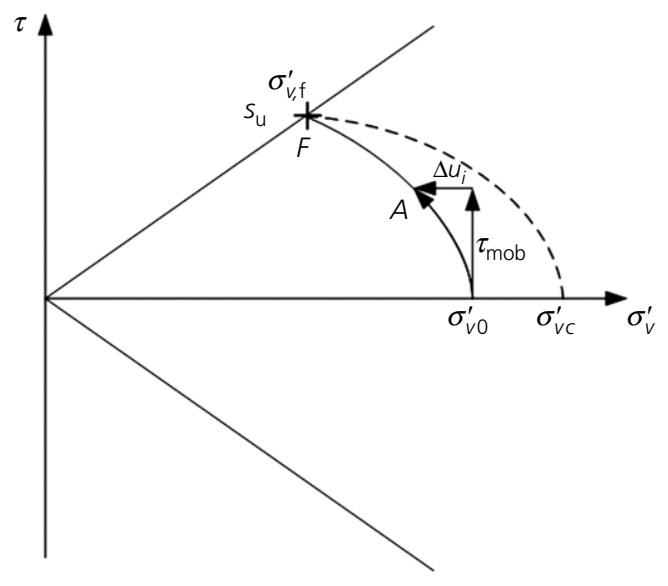

Fig. 10. Stress paths and notation for method 3 to predict changes in undrained strength

where $R$ is the normally consolidated undrained strength ratio, determined from a test at OCR $=1$. A value of $R=0 \cdot 27$ is used in Fig. 8. The current OCR prior to shearing is defined treating the $K_{0}$ consolidated line as the normally consolidated line (NCL).

$$
\mathrm{OCR}=\frac{\sigma_{v c}^{\prime}}{\sigma_{v 0}^{\prime}}
$$

Following Yasuhara (1994), a quasi-OCR can be defined along a constant volume line as

$$
\mathrm{OCR}_{q}=\frac{\sigma_{v e}^{\prime}}{\sigma_{v 0}^{\prime}}
$$

Using the quasi-OCR, the current strength can always be written as

$$
s_{\mathrm{u}}=R \sigma_{\mathrm{ve}}^{\prime}=R \mathrm{OCR}_{\mathrm{q}} \sigma_{\mathrm{vo}}^{\prime}
$$

The different definitions of OCR are related by geometry of the unload-reload and CSLs with gradients $\kappa$ and $\lambda$ (Ladd \& Foot, 1974; Ladd, 1991; Mayne et al., 2009)

$$
\mathrm{OCR}_{\mathrm{q}}=\mathrm{OCR}^{1-\kappa / \lambda}=\mathrm{OCR}^{\Lambda}
$$

where $\Lambda=1-\kappa / \lambda$ and is $0 \cdot 7-0 \cdot 95$ for most soils. 
Calculation of pore pressure generated in response to a shear stress:

The vertical effective stress at failure is taken to be

$$
\sigma_{\mathrm{vf}}^{\prime}=\frac{s_{\mathrm{u}}}{\tan \phi^{\prime}}
$$

which is a common approach with the shear strength being at the top of the Mohr's circle (Carraro, 2017).

The pore pressure generated during shearing to failure is

$$
\Delta u_{\max }=\sigma_{v 0}^{\prime}-\sigma_{v f}^{\prime}=\sigma_{v 0}^{\prime}-\frac{s_{\mathrm{u}}}{\tan \phi^{\prime}}
$$

Combining (10) with (4) and (6), the following expression results:

$$
\frac{\Delta u_{\max }}{\sigma_{v 0}^{\prime}}=1-\frac{R \mathrm{OCR}_{\mathrm{q}}}{\tan \phi}
$$

The pore pressure generated during shearing towards failure is a fraction of $\Delta u_{\max }$ that depends on the shape of the stress path, which can be defined by

$$
\frac{\Delta u_{i}}{\Delta u_{\max }}=\left(\frac{\tau_{\mathrm{mob}}}{s_{\mathrm{u}}}\right)^{\beta}
$$

where $\beta>1$ (Cocjin et al., 2017). A value of $\beta=1 \cdot 25$ was used in Fig. 8, selected by way of fitting $\beta$ to the monotonic test data and predicted increases in $s_{\mathrm{u}}$ using methods 1 and 2 .

\section{Calculation of the change in strength due to pore-pressure dissipation}

To calculate the change in strength from a cycle of pore-pressure generation and dissipation, only $\mathrm{OCR}_{\mathrm{q}}$ needs to be updated because $\sigma_{\mathrm{v} 0}^{\prime}$ is constant between cycles. Therefore, $s_{\mathrm{u}}$ can be calculated according to (8)-(10). Furthermore, the change in void ratio during the dissipation phase can be expressed as

$$
\begin{aligned}
\Delta e & =-\kappa \ln \left(\frac{\sigma_{v 0}^{\prime}-\Delta u_{i}}{\sigma_{v 0}^{\prime}}\right) \\
& =-\kappa \ln \left(1-\frac{\Delta u_{i}}{\sigma_{v 0}^{\prime}}\right) \text { and } \Delta e=\lambda \ln \left(\frac{\sigma_{v e, i+1}^{\prime}}{\sigma_{v e, i}^{\prime}}\right)
\end{aligned}
$$

Therefore,

$$
\frac{\sigma_{v e, i+1}^{\prime}}{\sigma_{v e, i}^{\prime}}=\left(1-\frac{\Delta u_{i}}{\sigma_{v 0}^{\prime}}\right)^{-\kappa / \lambda}=\left(1-\frac{\Delta u_{i}}{\sigma_{v 0}^{\prime}}\right)^{\Lambda-1}
$$

Equation (14) allows the quasi-OCR to be updated

$$
\begin{aligned}
\left(\mathrm{OCR}_{\mathrm{q}}\right)_{i+1} & =\left(\mathrm{OCR}_{\mathrm{q}}\right)_{i} \times \frac{\left(\sigma_{\mathrm{ve}}^{\prime}\right)_{i+1}}{\left(\sigma_{\mathrm{ve}}^{\prime}\right)_{i}} \\
& =\left(\mathrm{OCR}_{\mathrm{q}}\right)_{i} \times\left(1-\frac{\Delta u_{i}}{\sigma_{\mathrm{v} 0}^{\prime}}\right)^{-\kappa / \lambda}
\end{aligned}
$$

and the updated undrained strength can be calculated from equation (7). The fractional increase in undrained strength can now be expressed as

$$
\frac{s_{u, i+1}}{s_{u, i}}=\left(1-\frac{\Delta u_{i}}{\sigma_{v 0}^{\prime}}\right)^{-\kappa / \lambda}
$$

\section{REFERENCES}

Abadie, C. N., Byrne, B. W. \& Houlsby, G. T. (2019). Rigid pile response to cyclic lateral loading: laboratory tests. Géotechnique 69, No. 10, 863-876, https://doi.org/10.1680/jgeot.16.P.325.
Airey, D. W. \& Wood, D. M. (1987). An evaluation of direct simple shear tests on clay. Géotechnique 37, No. 1, 25-35, https://doi. org/10.1680/geot.1987.37.1.25.

Airey, D. W., Budhu, M. \& Wood, D. M. (1985). Some aspects of the behaviour of soils in simple shear. In Developments in soil mechanics and foundation engineering: vol. 2: stress-strain modelling of soils (eds P. K. Banerjee and R. Butterfield), pp. 185-213. London, UK: Elsevier Applied Science Publishers.

Andersen, K. H. (2015). Cyclic soil parameters for offshore foundation design. In Frontiers in Offshore Geotechnics III (ed. V. Meyer), vol. 1, pp. 5-82. Leiden, The Netherlands: CRC Press.

ASTM (2007). D6528: Standard test method for consolidated undrained direct simple shear testing of cohesive soils. West Conshohocken, PA, USA: ASTM International.

Bayton, S. M., Black, J. A. \& Klinkvort, R. T. (2018). Centrifuge modelling of long term cyclic lateral loading on monopiles. In Physical modelling in geotechnics - ICPMG 2018 (eds A. McNamara, S. Divall, R. Goodey, N. Taylor, S. Stallebrass and J. Panchal), pp. 689-694. London, UK: CRC Press.

Boukpeti, N. \& White, D. J. (2017). Interface shear box tests for assessing axial pipe-soil resistance. Géotechnique 67, No. 1, 18-30, https://doi.org/10.1680/jgeot.15.P.112.

Carraro, J. A. H. (2017). Analysis of simple shear tests with cell pressure confinement. Geomech. Geoengng 12, No. 3, 169-180.

Cocjin, M., Gourvenec, S., White, D. J. \& Randolph, M. F. (2014). Tolerably mobile subsea foundations - observations of performance. Géotechnique 64, No. 11, 895-909, https://doi.org/10. 1680/geot.14.P.098.

Cocjin, M., Gourvenec, S., White, D. J. \& Randolph, M. F. (2017). Theoretical framework for predicting the response of tolerably mobile subsea installations. Géotechnique 67, No. 7, 608-620, https://doi.org/10.1680/jgeot.16.P.137.

Dyvik, R., Berre, T., Lacasse, S. \& Raadim, B. (1987). Comparison of truly undrained and constant volume direct simple shear tests. Géotechnique 37, No. 1, 3-10, https://doi.org/10.1680/geot.1987. 37.1.3.

Gourvenec, S. (2018). The role of centrifuge modelling on capturing whole-life response for optimization of offshore foundation design. Keynote Proceedings of the 9th international conference on physical modelling in geotechnics, ICPMG (eds A. McNamara, S. Divall, R. Goodey, N. Taylor, S. Stallebrass and J. Panchal), pp. 51-75. London, UK: Taylor \& Francis.

Gourvenec, S. (2020). Whole-life geotechnical design: What is it? What's it for? So what? And what next? Proceedings of the 4th international symposium on frontiers in offshore geotechnics (delayed to) 8-11 November 2021, proceedings published Aug 2020 (ed. Z. Westgate), pp. 206-246. Austin, TX, USA: Deep Foundations Institute.

Han, C., Wang, D., Gaudin, C., O’Loughlin, C. D. \& Cassidy, M. J. (2016). Behaviour of vertically loaded plate anchors under sustained uplift. Géotechnique 66, No. 8, 681-693, https://doi. org/10.1680/jgeot.15.P.232.

Hodder, M. S., White, D. J. \& Cassidy, M. J. (2013). An effective stress framework for the variation in penetration resistance due to episodes of remoulding and reconsolidation. Géotechnique $\mathbf{6 3}$, No. 1, 30-43, https://doi.org/10.1680/geot.9.P.145.

Kinner, E. \& Ladd, C. C. (1973) Undrained bearing capacity of footings on clay. Proceedings of 8th International Conference on Soil Mechanics and Foundation Engineering, vol. 1, Moscow, pp. 209-215.

Ladd, C. C. (1991). Stability evaluation during staged construction. J. Geotech. Engng 117, No. 4, 540-615, 22nd Karl Terzaghi Lecture.

Ladd, C. C. \& Foot, R. (1974). New design procedure for stability of soft clays. J. Geotech. Engng Div. 100, No. GT7, 763-786.

Lai, Y., Wang, L., Hong, Y. \& He, B. (2020). Centrifuge modeling of the cyclic lateral behavior of large-diameter monopiles in soft clay: effects of episodic cycling and reconsolidation. Ocean Engng. 200, No. 2020, 107048

Mayne, P. W. (1985). A review of undrained strength in direct simple shear. Soils Found. 25, No. 3, 64-72.

Mayne, P. W., Coop, M. R., Springman, S. M., Huang, A. B. \& Zornberg, J. G. (2009). SOA-1: Geomaterial behavior and testing. In Proceedings of the 17th International Conference on 
Soil Mechanics and Geotechnical Engineering, vol. 4, pp. 27772872. Rotterdam, the Netherlands: Millpress.

O'Loughlin, C. D., White, D. J. \& Stanier, S. A. (2017). Plate anchors for mooring floating facilities-a view towards unlocking cost and risk benefits. In Proceedings of the 8th Offshore Site Investigation Geotechnics International Conference Proceeding, Vol. 2, pp. 978-986. London, UK: Society for Underwater Technology.

Randolph, M. P. (2000). Effect of strength anisotropy on capacity of foundations. In Developments in Theoretical Geomechanics: The John Booker Memorial Symposium (eds D. W. Smith and J. P. Carter), pp. 313-327. Rotterdam, The Netherlands: CRC Press/Balkema.

Richards, I. A., Byrne, B. W. \& Houlsby, G. T. (2018). Physical modelling of monopile foundations under variable cyclic lateral loading. In Physical modelling in geotechnics, vol. 1, pp. 737-741. London, UK: CRC Press.

Richards, I. A., Byrne, B. W. \& Houlsby, G. T. (2019). Monopile rotation under complex cyclic lateral loading in sand. Géotechnique, 70, No. 10, 916-930, https://doi.org/10.1680/ jgeot.18.P.302.
Schofield, A. \& Wroth, P. (1968). Critical state soil mechanics. Berkshire, UK: McGraw-Hill.

Smith, V. B. \& White, D. J. (2014). Volumetric hardening in axial pipe soil interaction. In Offshore Technology Conference-Asia. Offshore Technology Conference, vol. 2, pp. 1611-1621.

Taylor, D. W. (1948). Fundamentals of soil mechanics. New York, NY, USA: John Wiley and Sons.

Truong, P., Lehane, B. M., Zania, V. \& Klinkvort, R. T. (2019). Empirical approach based on centrifuge testing for cyclic deformations of laterally loaded piles in sand. Géotechnique 69, No. 2, 133-145, https://doi.org/10.1680/jgeot. 17.P.203.

Yasuhara, K. (1994). Postcyclic undrained strength for cohesive soils. J. Geotech. Engng 120, No. 11, 1961-1979.

Yasuhara, K. \& Andersen, K. H. (1991). Recompression of normally consolidated clay after cyclic loading. Soils Found. 31, No. 1, 83-94.

Zhou, Z., O'Loughlin, C. D., White, D. J. \& Stanier, S. A. (2019). Improvements in plate anchor capacity due to cyclic and maintained loads combined with consolidation. Géotechnique 70, No. 8, 1-18, https://doi.org/10.1680/jgeot.19.TI.028. 